China

\section{The One Child Family Policy}

W X Zhu

\section{The government hopes that there will be a shift towards the "small family culture"}

W hat is known as the One Child Policy was introduced in 1979 as a set of rules and regulations governing the approved size of Chinese families. This was not the first attempt by China to curb the growth of its population. The so called "late, long, few" policy was introduced in the early 1970 , because the population had risen dramatically during the 1950s and 60s, from 540 million in 1950 to 850 million in 1970. The "late, long, few" policy was a conventional family planning programme, consisting of the encouragement of later child bearing, longer spacing, and fewer children. This policy led to a fall in the total fertility rate (TFR) from 5.9 in 1970 to 2.7 in $1979 .{ }^{1}$ But this fall was not enough for Deng Xiao Ping who at this time was setting out his economic reform programme. Projections showed that the population would continue to rise sharply, because around two thirds of the population were under 30, and because the baby boomers of the 1950s and 60s were entering their reproductive years. Deng saw population containment as essential to the success of his economic reform programme. ${ }^{2}$ So the One Child Policy was introduced. Twenty three years later the TFR is estimated to be 1.8 , and it has remained unchanged for the past five years. ${ }^{3}$

There is much confusion about the policy, mainly because in this vast country the way in which the policy is actually implemented varies considerably from place to place. ${ }^{4}$ For example, families of four and more are still tolerated (though not officially allowed) in some remote rural areas, while a strict one child per family policy is imposed in the cities There is a central policy making body, the State Family Planning Committee, which is a separate and powerful government department. This bureau sets targets and provides guidelines on implementation, but it is the family planning committees at provincial level who make decisions about actual implementation. The imposing of penalties is usually left to local cadres. This explains the wide variation in practice.

In Chinese cities only one child is allowed with a few exceptions: firstly, in the case of second marriage where one partner has not had a child; secondly, if the first child has an abnormality or a condition which will reduce life expectancy (there is a list of such conditions and a doctor is required to provide the necessary proof); thirdly, if the father is in a dangerous occupation, such as mining; and fourthly, where both spouses are only children. This latter is important, since the first cohort of only children are now reaching their reproductive years and more and more couples will fulfil this requirement.

But the policy is more relaxed in the countryside where around $70 \%$ of the population live. Here, with the exception of government workers, two children are permitted, if the first is a girl, and provided there is a four year gap. This clearly acknowledges the traditional preference for boys, which is still the case, particularly in rural areas. Third children are allowed for some minority ethnic groups

\section{"The whole programme is underpinned by a massive health education campaign"}

Late marriage and spacing still play an important role. Marriage is not permitted until age 25 for men and 23 for women in cities, ages 23 and 21 respectively in rural areas. The whole programme is underpinned by a massive health education campaign: the messages tend to focus on the societal dangers of overpopulation and the personal material benefits of having only one child.

Modes of enforcement and penalties vary widely. In many rural areas flouting of the regulations is not rare. It is difficult for local cadres to enforce unpopular regulations in their own small communities. If a woman becomes pregnant outside the policy there is pressure to have an abortion. Nowadays there is considerable acceptance of this in the cities, at least. If an "illegal" pregnancy is carried to term, there is a range of penalties for failure to comply. If the parents are government workers or employed by state owned enterprises this will mean loss of employment. But for the majority the punishment includes fines, loss of benefits for the first child, and higher charges for obstetric care. ${ }^{6}$ In extreme cases women who become pregnant outside the policy may leave their hometowns to deliver elsewhere, in a place they are not known. The new mobility of the rural workforce has made such evasion of the authorities much easier.

In the West there has been much criticism of the Policy as a violation of the human right to reproduce. Even the Chinese Government would agree that denying individuals the right to have as many children as they want is not desirable. But the Policy is seen as a necessity in the short term. In particular, in recent years the Government sees that restriction of family size is fundamental to its ongoing poverty alleviation programme: to break the vicious cycle of poverty leading to more children, which in turn generates more poverty.

Apart from curbing population growth, the policy has had a number of beneficial effects. Women have access to contraception and safe legal abortion. Mothers are freed from the burden of many pregnancies with the associated morbidity and mortality. They also have more freedom to work outside the home, acquire skills, and contribute to the household income, with resulting benefits in terms of independence and self esteem. Children benefit from the increased resources devoted to them. ${ }^{8}$ ' Only daughters may particularly benefit from not having to compete for resources with sons.

"The policy has contributed to gender imbalance in rural areas"

But there is of course a negative side. The policy has contributed to gender imbalance in rural areas, with an excess of male births reported in some areas. $^{10-12}$ The 1995 population survey reported average male:female ratios of 108:100 in rural areas. ${ }^{13}$ But this is not just because of sex selective abortion (which is now illegal, ${ }^{14}$ though undoubtedly still occurs), but also because of failure to report female births. Female infanticide is probably extremely rare now. When the Policy was introduced there were concerns about support for the elderly. ${ }^{15}$ In urban areas around 70\% of the population have some form of pension, but in rural areas care and support for the elderly remains the responsibility of offspring. With small families care for the elderly becomes a considerable burden.

Finally, there is the issue of the health and psychological effects of being an only child. This is the question asked by Hesketh et al in this issue. ${ }^{16}$ Much has been made of the over indulged Little Emperors of contemporary China, ${ }^{17}$ but there is little hard evidence that they are any more spoilt than their contemporaries in other part of East Asia or even the West. $^{89^{18}}$ Over the past generation disposable incomes have increased for the 


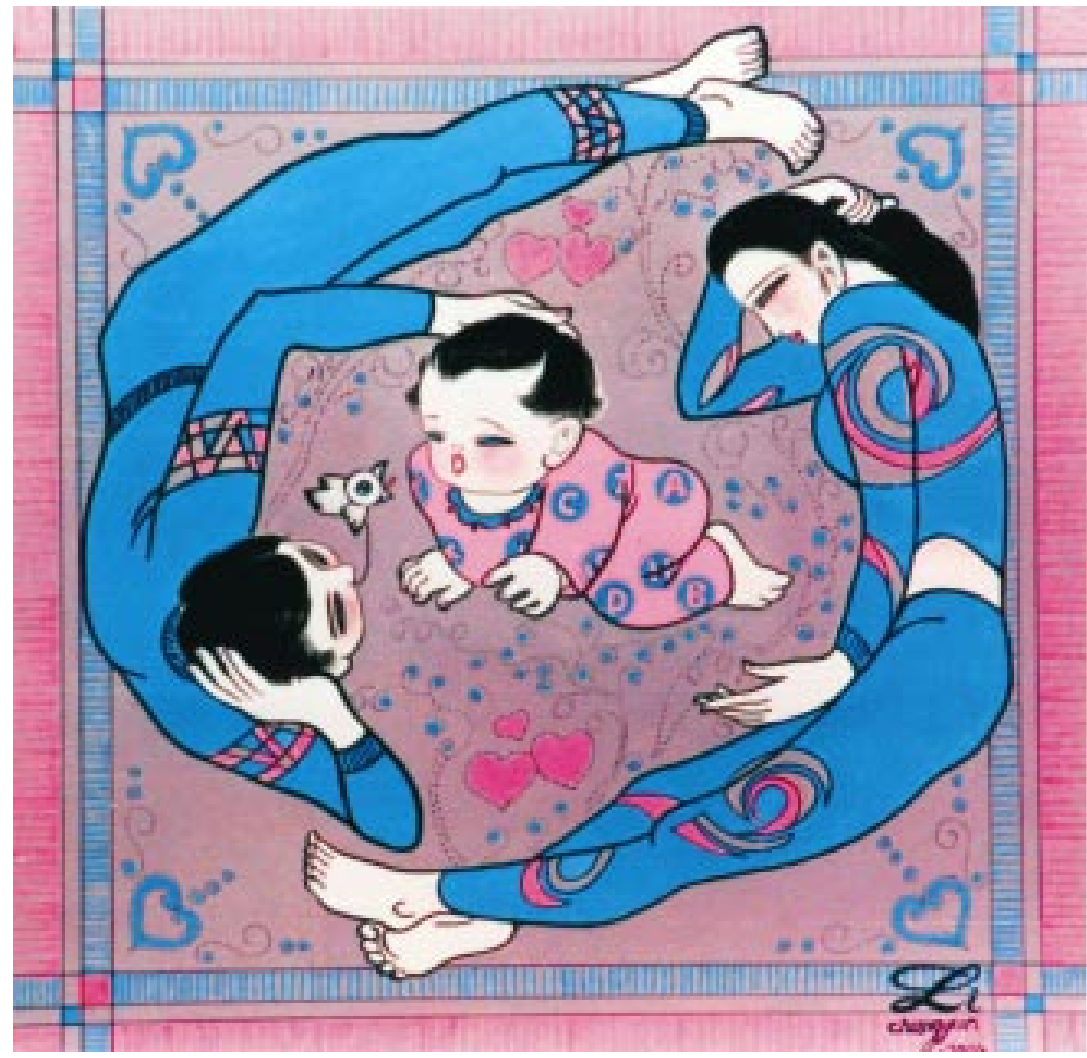

A chinese couple with one child in a yin-yang posture representing male-female balance. Painting by Li Chang Yun, Health Education Department, Xiaoshan MCH Hospital.

majority, and combined with greater access to goods and commodities and freedom to travel, this means that for many children there are huge opportunities, irrespective of the family size. One of the problems with any research in this area is that it is likely to be confounded by socioeconomic differences, given that those couples who are allowed to have more than one child are generally from lower income and education groups. This is why Hesketh et al's analysis of only and sibling children in one wealthy county is particularly welcome. After controlling for potential confounders they found very small differences between sibling families and one child families and concluded that being an only child may actually confer some benefits.

It was never intended that the Policy would last forever. ${ }^{19}$ The Chinese government has achieved fairly widespread acceptance for a strict family limitation policy. ${ }^{4}$ However, increasing wealth and employment freedom mean that communal pressure and economic disincentives will not be enough to contain the population in the future. The government hopes that there will be a shift towards the "small family culture" underpinned by improved living standards, guaranteed survival of children, and security in old age. ${ }^{19}$ (It is interesting to note that the small family culture is the norm in Hong Kong where the policy is not in force and the TFR is just 1.l. ${ }^{3}$ ) There is evidence that there is growing acceptance of small families in China, ${ }^{20}{ }^{21}$ so much so that in 30 pilot counties the policy has been lifted, allowing couples to choose their family size. ${ }^{22}$ A possible scenario for the future is allowing all couples to have two children, with a five year gap in both urban and rural areas. ${ }^{19}$ This would be more popular and would be perceived as fairer. Research like that by Hesketh et al, which suggests that the One Child Policy may not do harm to children and adolescents, should help to allay some of the fears held by opponents of the policy.

Arch Dis Child 2003;88:463-464
Author's affiliation

W X Zhu, Health Unlimited, East Asia

Correspondence to: Dr W X Zhu, Apt 2-401 Ya shi Yuan, 39 NanZhong Guo Xin Chen, 149 Wen Hua Road, Hangzhou, Zh 210012 , China; huchn@mail.hz.zi.cn

\section{REFERENCES}

1 Yao XW, Yin H. Basic data of China's population. Beijing: China Population Publishing House, 1994

2 Christiansen F, Rai S. Chinese politics and society. Prentice Hall, 1996.

3 United Nations Population Fund. www.un.org/popin/data. Accessed 20 December 2002

4 Hesketh T, Zhu WX. The one child family policy: the good, the bad and the ugly. BM 1997:314:1685-7.

5 Green L. Promoting the one child policy in China. J Public Health Policy 1988;6:273-8.

6 Doherty JP, Norton EC, Veney JE. China's one-child policy: the economic choices and consequences faced by pregnant women. Soc Sci Med 2001;52:745-61.

7 Anon. An integration programme of poverty alleviation and development with family planning. China Population Today 1997; 14(2):6

8 Wang Z. Psychology in China: a review dedicated to Li Chen. Annu Rev Psychol 1993:44:87-116.

9 Jing Q, Wan C, Over R. Single child family in China: psychological perspectives. Int J Psychol 1987;22:127-38.

10 Hull TH. Recent trends in sex ratios at birth in China. Popul Dev Rev 1990;16:62-5.

11 Wen X. Effect of son preference and population policy on sex ratios at birth in two provinces in China. J Biosoc Sci 1993:25:509-21.

12 Poston DL Jr. Son preference and fertility in China. J Biosoc Sci 2002;34:333-47.

13 Zhu B. China's population growth slower survey finds. China Daily, 15 February 1996.

14 Anon. Sex identification of fetus banned by law. China Population Today 1998;15(5-6):4.

15 Yang Q. The aging of China's population: perspectives and implications. Asia Pac Popul J 1988:3:55-74.

16 Hesketh T, Qu JD, Tomkins A. Health effects of family size: cross sectional survey in Chinese adolescents. Arch Dis Child 2003:88:467-71.

17 Chen B. A little emperor. One Child family. Integration 1994;(39):27.

18 Jiao S, Ji G, Jing Q. Comparative study of behavioural qualities of only children and sibling children. Child Dev 1986;57:357-61.

19 Greenhalgh S, Bongaarts J. Fertility policy in China: future options. Science 1987:235: 1 167-72.

20 Merli MG, Smith HL. Has the Chinese family planning policy been successful in changing fertility preferences? Demography 2002;39:557-72.

21 Yu P. Chinese youth favour one-child families. Population Today 1995;23(4):4-5

22 Hesketh T, Zhu WX. Human population policy: The one child family policy is changing. BM 1999;319:223. 